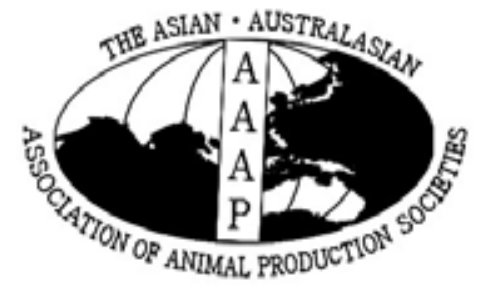

Asian-Aust. J. Anim. Sci.

Vol. 20, No. $1: 12$ - 18

January 2007

www.ajas.info

\title{
Selection of Sahiwal Cattle Bulls on Pedigree and Progeny
}

\author{
A. A. Bhatti, M. S. Khan*, Z. Rehman, A. U. Hyder and F. Hassan \\ Department of Animal Breeding and Genetics, University of Agriculture Faisalabad 38040, Pakistan
}

\begin{abstract}
The objective of the study was to compare ranking of Sahiwal bulls selected on the basis of highest lactation milk yield of their dams with their estimated breeding values (EBVs) using an animal model. Data on 23,761 lactation milk yield records of 5,936 cows from five main Livestock Experiment Stations in Punjab province of Pakistan (1964-2004) were used for the study. At present the young A.I bulls are required to be from A-category bull-dams. Dams were categorized as A, B, C and D if they had highest lactation milk yield of $\geq 2,700,2,250-2,699,1,800-2,249$ and $<1,800$ litres, respectively. The EBVs for lactation milk yield were estimated for all the animals using an individual animal model having fixed effect of herd-year and season of calving and random effect of animal. Fixed effect of parity and random effect of permanent environment were incorporated when multiple lactation were used. There were 396 young bulls used for semen collection and A.I during 1973-2004. However, progeny with lactation yields recorded, were available only for 91 bulls and dams could be traced for only 63 bulls. Overall lactation milk yield averaged 1,440.8 kg. Milk yield was $10 \%$ heritable with repeatability of 39\%. Ranking bulls on highest lactation milk yield of their dams, the in-vogue criteria of selecting bulls, had a rank correlation of $0.167(\mathrm{p}<0.190)$ with ranking based on EBVs from animal model analysis. Bulls' EBVs for all lactations had rank correlation of $0.716(\mathrm{p}<0.001)$ with EBVs based on first lactation milk yield and $0.766(\mathrm{p}<0.001)$ with average EBVs of dam and sire (pedigree index). Ranking of bulls on highest lactation yield of their dams has no association with their ranking based on animal model evaluation. Young Sahiwal bulls should be selected on the basis of pedigree index instead of highest lactation yield of dams. This can help improve the genetic potential of the breed accruing to conservation and development efforts. (Key Words : Sahiwal Cattle, Bull Selection, Pedigree, Progeny, Milk Yield)
\end{abstract}

\section{INTRODUCTION}

Among the indigenous cattle breeds, Sahiwal is the most prominent dairy breed of Pakistan. Sahiwal cattle are considered the "best zebu milch breed in the tropics" (Maule, 1990) and are well known for their disease resistance, heat tolerance and adequate performance at low quality roughages (Nay and Hayman, 1956; Dahlin et al., 1998). Due to its promising adaptability to tropical and subtropical environment and reasonable dairy performance, both semen and cows of Sahiwal breed have been exported to many countries. Sahiwal has been used for the development of other breeds like Australian Friesian Sahiwal (Alexander et al., 1984), Australian Milking Zebu (Hayman, 1974), Indian Frieswal (Mudgal et al., 1992), Karan Swiss (Yadav and Dubey, 1979), Jamaica Hope (Wellington and Mahadevan, 1977), Malaysian Mafriwal (Selvi et al., 2004), Tanzanian, Mpwapwa (Syrstad, 1990) and Taurindicus (Anonymous, 2005) in New Zealand. It has

* Corresponding Author: M. Sajjad Khan. Tel: +92-41-9200162 (Ext 3202), Fax: +92-41-2625191, E-mail: drsajjad2@yahoo.com Received October 11, 2005; Accepted September 13, 2006 also been used for upgradation of other breeds such as Pabna in Bangladesh (Bhuiyan et al., 1998). Within Pakistan, this breed is mainly found in central and southern parts of Punjab, the original hometract of this breed. Population estimates of the breed vary widely. Estimate in the last livestock census was 1.4 million (GOP, 1996) which was $6.8 \%$ of the total cattle population in the country. Later, percentage of this breed in the total cattle population was reported to be $5 \%$ (Ahmad et al., 2000). Lower population estimates of 9,000 and 10,500 breedable cows have also been reported (Payne and Hodges, 1997). A major reason for deterioration of population is crossbreeding with exotics such as Holstein for higher milk yield.

Sahiwal population has not improved in its ability to produce milk and many studies point to that. Ahmad (1972) reported that little genetic improvement in milk yield at one of the institutional Sahiwal herd (Allahdad Cattle Farm Jahanian, Khanewal) $(0.18 \%$ of the herd mean) was due to selection of bull dams. Selection based on type and conformation were described as major factors for the low genetic gain. Talbott et al. (1997) reported that in Sahiwal herd at Livestock Experiment Station Bahadurnagar, Okara, 
regression of breeding values for milk yield on birth year of cows was $-61 \mathrm{~kg}$, pointing that genetic trend in the herd was negative and cows deteriorated in their ability to produce milk at 5\% per year. Data for this study pertained to $1974-$ 1989. Dahlin et al. (1998) analysed performance records of about 5,200 cows from 11 institutional herds in Punjab over a span of 20 years. In spite of appreciable variation in milk yield, genetic trend was close to zero. Alternate selection strategy showed that annual genetic gain in the range of 0.7 to $1.1 \%$ was possible and a large number of young bulls in breeding would be beneficial both to achieve the desired gain and improve effective population size. Later on, Javed (1999) reported that in the Sahiwal herd at Livestock Experiment Station, Jahangirabad, Khanewal (1937-1997), there was wide fluctuation in estimated breeding values of milk yield across years but no overall change in breeding values. Absence of effective selection and culling program was described as the major reason for no genetic improvement. Recently Rehman (2006) has reported that for the five major Sahiwal herds in Punjab, lactation milk yield has been decreasing over the years and both phenotypic and genetic trends were negative.

Phenotypic and genetic trends in Sahiwal breed in other parts of the world have been variable. Studies on Sahiwal herds in India indicate that some of the herds may have positive genetic trend for first lactation milk yield while other herds had negative genetic trend (Singh, 1981). Kumar and Narain (1979) reported a negative genetic trend (-27 litres) for Chak Ganjaria herd while Singh (1992) reported a positive genetic trend (46 litres) for Hisar herd. Other studies (Singh and Nagarcenkar, 2000; Raja, 2004) indicated that genetic trend was positive (16-77 litres) for the Karnal herd of Sahiwal in India.

One of the major reasons for deterioration in Sahiwal breed could be the selection criteria used for selecting bulls. Bulls are selected on the basis of performance of their dams. Dams are categorized as A, B, C and D if they have highest lactation milk yield of $\geq 2,700,2,250-2,699,1,800-2,249$ and $<1,800$ litres, respectively. Bulls fulfilling the breed characteristics are chosen from A-category dams and used in the artificial insemination program. Progeny testing has also been started to widen the genetic base and achieve permanent improvement in traits like milk yield. The recently established Research Center for Conservation of Sahiwal Cattle (RCCSC) has started registration of Sahiwal cows in 2004 and recording for milk yield and other traits. The aforementioned selection strategy, which has resulted in the zero genetic progress, thus needs to be looked into and alternatives need to be explored to make selection at farm and at population level, effective.

Best Linear Unbiased Predictions (BLUP) procedure using Animal Model has become the world wide standard for the prediction of breeding values of farm animals. It is the most appropriate procedure to achieve accurate estimates of breeding values for the following reasons: it provides minimum variance for unbiased predictors of genetic merit; it estimates genetic and environmental effects simultaneously; it takes into account the relationship between all animals, thus accounting for the effects of selection and non random matings; animals can be compared across herds and years and evaluations across years facilitate monitoring for the rates of genetic progress (Hill and Meyer, 1988). The objective of the present study was to estimate breeding values of Sahiwal bulls for lactation milk yield using an animal model and compare their ranking with the procedure of selecting bulls on the best lactation milk yield of their dams.

\section{MATERIALS AND METHODS}

Multiple lactation records of Sahiwal cows maintained at different Government Livestock Experiment Stations (LESs) were used for the present study. Names of these LESs along with duration of records are as follows:
LES Allahdad, Distt. Khanewal (1964-1991)
LES Bahadurnagar, Distt. Okara (1970-2004)
LES Fazalpur, Distt. Rajanpur (1980-2004)
LES Jahangirabad, Distt. Khanewal (1965-2004)
LES Khizerabad, Distt. Sargodha (1980-2004)

Milk yield and lactation length records were procured from these LESs for estimating breeding values of cows and bulls for lactation milk yield upto 305-days. Lactations were required to be at least of 2-weeks duration. There were 396 Sahiwal bulls brought to Semen Production Unit (SPU), Qadirabad for A.I since its inception in 1972. Information of these regarding dams yield was available on most of the bulls received from Livestock Experiment Stations with Livestock and Dairy Development Department of Punjab but in many cases the highest lactation yields recorded for these bulls did not match with the yields on the history sheets of their dams. Out of the 396 bulls, progeny with lactation yields were available for 91 bulls. Of these 91 bulls dams (having lactation yield recorded) could be traced for 63 bulls only. Of the 396 bulls brought to SPU from 1973-2004, 155 bulls (39\%) were supplied by the LES Bahadurnagar and 102 bulls (26\%) by LES Jahangirabad. The LES Khizerabad provided 45 bulls. Some 42 bulls had been received from private breeders, mostly with no records on their dams. The LES Allahdad provided 31 bulls.

Pedigree and lactation milk yield information on all the animals in the data set was used to find estimated breeding values (EBVs) for bulls and cows. All known relationships and important environmental sources of variation. The model had herd-year of calving, season of calving and 
Table 1. Number of observations and mean lactation milk yield for different parities and season of calving

\begin{tabular}{ccc}
\hline Source of variation & $\begin{array}{c}\text { Number of } \\
\text { observations }\end{array}$ & Mean \\
\hline Parity & 5,739 & $1,287.3$ \\
1 & 4,610 & $1,468.4$ \\
2 & 3,679 & $1,537.3$ \\
3 & 2,918 & $1,528.0$ \\
4 & 2,261 & $1,552.3$ \\
5 & 1,657 & $1,496.6$ \\
6 & 1,222 & $1,451.9$ \\
7 & 803 & $1,387.5$ \\
8 & 456 & $1,335.9$ \\
9 & 416 & $1,142.4$ \\
10 & & \\
Season of calving & 8,480 & $1,496.4$ \\
Winter & 6,505 & $1,416.0$ \\
Spring & 4,593 & $1,386.6$ \\
Summer & 4,183 & $1,426.1$ \\
Autumn & 23,761 & $1,440.8$ \\
Overall & & \\
\hline
\end{tabular}

parity as fixed effects. Random effects were individual animal and permanent environment.

$\mathrm{Y}_{\mathrm{ijklm}}=\mathrm{HY}_{\mathrm{i}}+\mathrm{S}_{\mathrm{j}}+\mathrm{L}_{\mathrm{k}}+\mathrm{A}_{\mathrm{l}}+\mathrm{P}_{\mathrm{l}}+\mathrm{e}_{\mathrm{ijklm}}$

Where:

$\mathrm{Y}_{\mathrm{ijklm}}=$ Lactation milk yield for any cow

$\mathrm{HY}_{\mathrm{i}}=\mathrm{i}^{\text {th }}$ herd-year of calving combination (1-169)

$\mathrm{S}_{\mathrm{j}}=\mathrm{j}^{\text {th }}$ season of calving (1-4)
$\mathrm{L}_{\mathrm{k}}=\mathrm{k}^{\text {th }}$ parity $(1-10)$

$\mathrm{A}_{\mathrm{l}}=\mathrm{l}^{\text {th }}$ animal effect (breeding value)

$\mathrm{P}_{1}=\mathrm{l}^{\text {th }}$ permanent environment effect

$\mathrm{e}_{\mathrm{ijklm}}=$ Random error

Model for estimation of breeding values for first lactation milk yield was similar to above model except that herd-year and season of calving were the only two fixed effects. There were 5,739 first calvers while there were 23,761 lactation records when all parities (upto 10) were considered. There were 253 sires represented in these data sets. Bulls were ranked on the basis of their dam's high lactation milk production. The four different categories, being used by Livestock and Dairy Development Department of Punjab (Anonymous, 2000) for selecting bulls under Artificial Insemination program were A $(>2,700$ lit), B (2,250-2,699 lit), C (1,800-2,249) and D ( $<1,800$ lit).

Spearman’s Rank correlations (Devore and Peck, 1986) were worked out between different methods of ranking bulls. Significance of correlations was tested to judge agreement or disagreement among various methods. Breeding values were estimated using DFREML (Meyer, 1997).

\section{RESULTS}

Number of observations and means for various parities and seasons of calving are presented in Table 1. Overall lactation milk yield for 23,761 lactations averaged 1,440.8

Table 2. Rank correlations among various parameters* that could potentially be used for ranking bulls $(\mathrm{n}=63)$

\begin{tabular}{|c|c|c|c|c|c|c|}
\hline Trait & $\begin{array}{c}\text { Bull's Dam's } \\
\text { highest yield } \\
\text { (1) }\end{array}$ & $\begin{array}{c}\text { Bull's daught. } \\
1^{\text {st }} \text { lactation average } \\
\text { (2) }\end{array}$ & $\begin{array}{l}\text { Bull's daught. } \\
\text { All-lactation } \\
\text { average } \\
\text { (3) }\end{array}$ & $\begin{array}{c}\text { Bull's EBV 1st } \\
(4)\end{array}$ & $\begin{array}{c}\text { Bull's EBV all } \\
\text { (5) }\end{array}$ & $\begin{array}{l}\text { Bull's Pedigree } \\
\text { index } \\
\text { (6) }\end{array}$ \\
\hline (1) & & -0.040 & -0.002 & 0.404 & 0.167 & 0.447 \\
\hline (2) & & & 0.775 & 0.282 & 0.512 & 0.274 \\
\hline (3) & & & & 0.170 & 0.235 & 0.052 \\
\hline (4) & & & & & 0.716 & 0.644 \\
\hline (5) & & & & & & 0.743 \\
\hline (6) & & & & & & \\
\hline \multicolumn{7}{|c|}{ Statistical significance } \\
\hline (1) & & 0.756 & 0.986 & 0.001 & 0.190 & 0.001 \\
\hline (2) & & & 0.001 & 0.025 & 0.000 & 0.030 \\
\hline (3) & & & & 0.182 & 0.064 & 0.687 \\
\hline (4) & & & & & 0.001 & 0.001 \\
\hline (5) & & & & & & 0.001 \\
\hline (6) & & & & & & \\
\hline
\end{tabular}

* Dam's highest yield = Highest lactation milk yield of bull-dam for any lactation.

Bull's daught. $1^{\text {st }}$ lact. average = Average first lactation milk yield of daughters of any bull.

Bull's daught. overall average = Average lactation milk yield (all lactations) of daughters of any bull.

Bull's EBV $1^{\text {st }}=$ Bull's estimated breeding values based on first lactation milk yields of its daughters and information on pedigree and performance of other relatives.

Bull's EBV all = Bull's estimated breeding values based on all lactation milk yields of its daughters and information on pedigree and performance of other relatives.

Bull's Pedigree index = Average of bulls' dam's EBV and sire's EBV. 


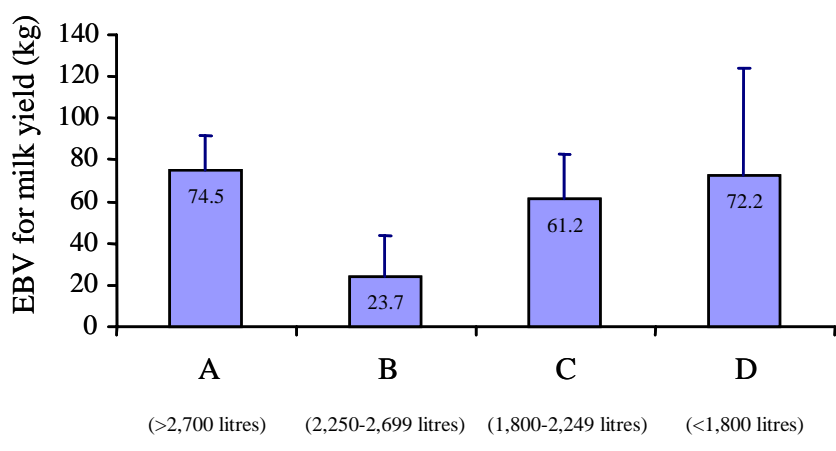

Dam's highest lactation milk yield (kg)

Figure 1. Average estimated breeding values for lactation milk yield of 63 bulls for various categories of bull-dams.

$\mathrm{kg}$ for the study period 1964-2004. Average first lactation milk yield was $1,287.3 \mathrm{~kg}$ for 5,739 cows. Thereafter milk yield increased upto $5^{\text {th }}$ parity $(1,552.3 \mathrm{~kg})$ and declined thereafter (Table 1). Season of calving observations were not distributed equally across the four seasons. Winter had highest number of observations $(8,480)$ and lactation yield was also the highest pointing that cows calving in the normal (most favorable calving season) tended to produce better $(1,496.4 \mathrm{~kg})$ as compared to cows calving in summer $(1,386.6 \mathrm{~kg})$. Comparing solutions for various seasons with respect to winter season revealed that autumn calvers were at the disadvantage of $145 \mathrm{~kg}$ of milk yield per lactation as compared with the winter calvers. Similarly, $10^{\text {th }}$ parity cows had $233 \mathrm{~kg}$ lower lactation milk yield than first calvers. Similarly, $3^{\text {rd }}$ parity cows had advantage of $183 \mathrm{~kg}$ as compared to first parity cows.

Phenotypic variance for first lactation milk yield was $296,249.26 \mathrm{~kg}^{2}$. About $10 \%$ of which comprised of additive genetic variance $\left(h^{2}=0.102\right)$. When all lactations were included, phenotypic variance increased to $363,160.74 \mathrm{~kg}^{2}$ with $9.9 \%$ contribution by additive genetic variance $\left(\mathrm{h}^{2}=\right.$ 0.099). Variance due to permanent environment was $107,571.61 \mathrm{~kg}^{2}$. Repeatability of lactation milk yield was 0.395 .

Table 2 contains information on rank correlations on various sources used to rank bulls. The first criteria to rank the bulls was highest lactation milk yield of dams, the invogue criteria of selecting bulls. This method of ranking bulls had a rank correlation of $0.167 \quad(\mathrm{p}<0.190)$ when ranking was based on all lactation milk yields of daughters and all known relationships (pedigree, progeny and other relatives) had been incorporated along with the important environmental sources of variation such as year-season of calving and parity. The correlation was not different from zero as indicated by the probability of 0.190 (given in the bottom half of the Table 2). Rank correlation between bulls EBVs for all lactations and EBVs based on first lactation milk yield had a rank correlation of $0.716(\mathrm{p}<0.0001)$.
Similarly, rank correlation between bulls' EBVs for all lactations had a rank correlation of $0.766(\mathrm{p}<0.0001)$ with average EBV of its dam and sire (pedigree index). Dividing the 63 bulls into categories on the basis of their dam's yield revealed that there were 31 A-category bulls. Bulls in B, C and D categories were 19, 9, 4, respectively. The average lactation milk yield EBVs of the four categories were 74.5, 23.7, 61.2 and $72.2 \mathrm{~kg}$, respectively (Figure 1).

For years 1973-2004, semen doses produced by various bulls at SPU Qadirabad varied widely. Number of bulls collected for semen varied between 9 and 102 per year. Average number of doses produced per bull varied between 724 and 5,746 doses. Maximum values had a range of 2,442 and 17,801 doses. When semen doses produced by various bulls (having information on EBVs from individual animal) was plotted against dam's lactation milk yield, correlation was 0.17 which was not different from zero.

\section{DISCUSSION}

Bulls supplied to SPU Qadirabad came from different sources but information expected to be available was missing for many of the bulls. One of the major problems was identification number which were multiple, prone to confusions and contradictions. As genetic evaluation heavily depends on pedigree and progeny relationships, authentification of pedigrees is required with replication of authenticated records at different places. Pedigree recording has problems even in advanced setups (Visscher et al., 2002) and technologies such as finger printing are being developed as an alternate to tagging and tattooing, there is no choice except to have precisely recorded pedigree and performance information on all bulls brought to the SPU and other similar units. The inaccurate records of dams of the bulls would be another factor to be resolved in future. If history sheets (individual animal record sheets) of dams of these bulls are brought to the unit when bulls are first brought for semen collection, situation can be improved. Bulls from private breeders, otherwise having superior type, had a similar problem. Highest lactation yields were not based on authentic/supervised records.

Performance of Sahiwal cows during different lactations and seasons of calving were similar to earlier studies on the breed. Ahmad (1993) used the data on 3,463 lactations of 1,085 Sahiwal cows from Livestock Experiment Station (LES) Bahadarnagar, Okara from 1966-91 and reported that average milk yield of the cows was 2,128 kg when lactation of 180 to 308 days were used. Dahlin et al. (1998) reported average yield of $1,477 \mathrm{~kg}$ for an average lactation length of 256 days upto three lactations in 11 institutional herds in Pakistan. Mohiuddin (1987) earlier used the data on 974 Sahiwal cows maintained at Livestock Production Research Institute Bahadarnagar, (Okara) from 1964-86 and reported 
that average first lactation milk yield was $1,603 \pm 12 \mathrm{~kg}$ for an average lactation length of 305 days. Ahmad (1972) previously had reported average first lactation milk yield of 2,058 $\pm 9 \mathrm{~kg}$ for 928 cows maintained during 1962-66 at LES Allahdad. For LES Jahangirabad, Javed (1999) reported average lactation milk yield of $1,980 \pm 11 \mathrm{~kg}$ for lactations having lactation length of 267 days after deleting records shorter than 150 days. Bajwa et al. (2004) used the data of weekly milk yield records on 661 Sahiwal cows calving during 1990-2000 at Livestock Experiment Station Bahadarnagar, Okara and reported average lactation milk yield of $1,475 \pm 651 \mathrm{~kg}$ for an average lactation length of $248 \pm 67$ days.

The studies on Sahiwal cattle in other countries also vary in reporting the average milk yield in the breed. Kumar and Narian (1979) reported an average lactation yield of $1,617 \mathrm{~kg}$ for a lactation length of 292 days. Nagarcenkar (1983) reported an average first lactation yield of 1,622 kg for an average lactation length of 300 days while Gandhi et al. (1995) reported average 305-day yield of $1659.9 \mathrm{~kg}$ ( $\mathrm{n}=$ 9,052) for lactations of 278 days duration. For Kenyan Sahiwal (Kimenye, 1981) average lactation yield of $1,455 \pm 10 \mathrm{~kg}$ (for an average lactation length of $274 \pm 0.8$ days) has been reported. A similar average of 1,663 kg has also been reported (Rege et al., 1992) in a later study.

An increase in lactation yield towards $3^{\text {rd }}$ or $5^{\text {th }}$ parity and decline thereafter has been reported by Khan (1997) and Javed (1999). Better performance of Sahiwal cows calving in milder than hot season has also been documented previously (Javed, 1999; Bajwa et al., 2004). Differences among various studies regarding the extent of variation in performance due to season is due to grouping of months into season, parities included and actual severity in temperature and fluctuation of fodder availability. Fitting season as a separate effect instead of cross-classifying it with herd-year was due to better contemporary groups (Khan et al., 1997; Dahlin et al., 1998). Heritability estimate for lactation milk yield obtained in the present study, both for first and all lactations are slightly lower than reported by Dahlin et al. (1998). Difference of 5\% (10\% vs. $15 \%)$ may be due to inclusion of 15 more years of data where environmental fluctuations have increased and consequently have masked the genetic component or may even be due to deterioration in recording as such.

Comparing in-vogue criteria of selecting bulls with EBVs using all sources of information was the most important component of the study. Based on the information from history sheets of bulls, of the 63 bulls, about half (31) were A-category bulls. The EBVs of the bulls were not different from C or D category bulls (Figure 1). Expectation was that all the 63 bulls belonged to A-category (dams had $>2,700$ liters milk yield in a lactation) and none to other categories and that all had above average EBVs. Actually, not only that pedigree information had a poor association with progeny information, exaggerated records such as highest lactation yield of dams (ignoring lactation length) were expected to have no association with EBVs (Khan, 1998a). Consequently, correlation between the two selection criteria was (0.169) not different from zero. Had these bulls been selected on the basis of average EBVs of their parents (pedigree index), better bulls could have been selected (correlation being 0.447) (Table 2). Correlation between EBVs and other phenotypic measures such as daughters' first lactation yield ( $\mathrm{r}=-0.040$ ) or average lactation yield ( $\mathrm{r}$ $=-0.002$ ) would also be wastage of time. The so-called elite dams get preferential treatment on all the institutional farms and thus make the selection of young bulls even more difficult. The only choice of selecting young bulls seems pedigree index based on EBVs of their parents which should be calculated periodically for accurate selection of bulls brought to SPUs. Unique number system would also help reduce confusions and contradictions.

Relationship between reproductive performance of AI bulls with the productive performance of their daughters has not been studied extensively. In this study, correlation between semen doses produced by a bull and its potential to transmit good genes for lactation milk yield was close to zero. Traits like scrotal circumference (SC) have been measured in the past for selecting AI bulls. It was also implied that selection of better SC would help in the selection for early puberty in the daughters of such bulls (Anonymous, 1995). Selection for better SC in bulls to improve age at first calving of their daughters have some evidence but recent studies have contrary evidence (Martinez-Velazquez et al., 2003). Many of the male fertility parameters have good genetic control and can be improved adequately (Ducrocq and Humblot, 1998) yet, genetic selection to improve milk yield and other traits in the population should not be confused with phenotypic selection for these traits.

\section{CONCLUSIONS}

Ranking of bulls on highest lactation yield information of their dams has no association with their ranking on animal model evaluation. For genetic improvement, the young Sahiwal bulls for artificial insemination program should be selected from genetically superior parents rather than dams' highest lactation yields. This can help improve the genetic potential of the breed accruing to conservation and development efforts.

\section{ACKNOWLEDGEMENTS}

Financial support for this study was provided by Agricultural Linkage Program funded project 
"Development of milk recording and genetic evaluation models in Sahiwal cattle” being run by Dr. Muhammad Sajjad Khan (P.I) at the Department of Animal Breeding and Genetics in University of Agriculture, Faisalabad (Pakistan).

\section{REFERENCES}

Ahmad, M. 1993. Studies on the persistency of lactation in Sahiwal cows. M. Sc. Thesis, Univ. Agric. Faisalabad.

Ahmad, M., A. Bukhari, F. Awan and M. N. Saeed. 2000. Punjab Livestock Census. Vol. 1. Livestock and Dairy Development Department, Punjab, Lahore.

Ahmad, Z. 1972. Genetic analysis of a purebred herd of Sahiwal cattle. Ph.D Thesis, West Pakistan Agric. Univ. Lyallpur (Faisalabad).

Alexander, G. I., G. K. Reason, G. M. R. Gale and C. H. Clark. 1984. The performance of Australian Friesian Sahiwal cattle. World Anim. Rev. 52:13-16.

Anonymous 1995. Production of Breeding Bulls in Punjab (Pakistan). Directorate of Livestock Farms. Livestock and Dairy Development Department of Punjab, Lahore.

Anonymous. 2000. Annual Report (1999-2000). Directorate of Livestock Farms. Livestock and Dairy Development Department of Punjab, Lahore.

Anonymous 2005. Taurindicus dairy cattle. http://www.ambreed. co.nz/index.html [accessed June, 2005].

Bajwa, I. R., M. S. Khan, M. A. Khan and K. Z. Gondal. 2004. Environmental factors affecting milk yield and lactation length in Sahiwal cattle. Pakistan Vet. J. 24(1):23-27.

Bhuiyan, A. K. F. H., S. S. Islam and M. S. Hussen. 1998. Effect of Sahiwalization on the performance of graded cattle at a rural area in Bangladesh. Proc. $6^{\text {th }}$ World Cong. Genet. Appl. Livest. Prod. Armidale, Australia (Jan. 11-16, 1998). 25:201-204.

Dahlin, A., U. N. Khan, A. H. Zafar, M. Saleem, M. A. Chaudhry and J. Philipsson. 1998. Genetic and environmental causes of variation in milk production traits of Sahiwal cattle in Pakistan. Anim. Sci. 66:307-318.

Devore, J. and R. Peck. 1986. Statistics - The exploration and Analysis of Data. West Publishing Co. St. Paul, MN (USA).

Ducrocq, V. and P. Humblot. 1998. Is selection on semen characteristics needed? Proc. Int. Workshop on Genetic Improvement of Functional Traits in cattle-Fertility and Reproduction, GRUB, Germany. Interbull Bull. 18:68-73.

Gandhi, R. S., M. Gurnani and A. Singh. 1995. Influence of non genetic factors on some of the economic traits of Sahiwal cattle. Indian J. Dairy Sci. 48:605-606.

GOP (Government of Pakistan). 1996. Livestock Census. All Pakistan Report. Agricultural Census Organization, Statistics Division, Lahore.

Hayman, R. H. 1974. The development of Australian Milking Zebu. World Anim. Rev. 11:31-35.

Hill, W. G. and K. Meyer. 1988. Developments in methods for breeding values and parameter estimation in livestock. In Anim. Breed. Opportunities. BSAP Occasional Publication 12:81-98.

Javed, K. 1999. Genetic and phenotypic aspects of some performance traits in a purebred herd of Sahiwal cattle in Pakistan. Ph.D. Thesis, Dept. Animal Breeding and Genetics,
Univ. Agric. Faisalabad.

Khan, M. S. 1997. Lactation curve of Sahiwal cattle. Pakistan Vet. J. 17(3):107-110.

Khan, M. S. 1998a. Breeding value estimation of dairy bulls: a review. Pakistan Vet. J. 18 (1):1-5.

Khan, M. S., A. Ali, S. Ali and M. Saleem. 1997. Seasonal grouping in year-season model for animal model evaluation of Sahiwal cattle. Asian-Aust. J. Anim. Sci. 10(1):75-78.

Kimenye, D. 1981. Production traits of Kenya Sahiwal cattle. Bulletin Anim. Health Prod. Africa. 29(2):121-124. Anim. Breed. Abst., 50:3647, 1982.

Martinez-Velazquez, G., K. E. Gregory, G. L. Bennett and L. D. VanVleck. 2003. Genetic relationships between scrotal circumference and female reproductive traits. J. Anim. Sci. 81:395-401.

Maule, J. P. 1990. The Cattle of the Tropics. University of Edinburgh Centre for Tropical Veterinary Medicine, Edinburgh.

Meyer, K. 1997. User Notes of DFREML. Version 3.0 $\alpha$. [http://agbu.une.edu.au/ kmeyer/DFREML/dfreml.v30.dos.ex e]

Mohiuddin, G. 1987. Studies on Sahiwal cattle in Pakistan: III. Genetic and phenotypic parameters of productive and reproductive traits. M. Sc. Thesis, Univ. Agric. Faisalabad.

Mudgal, V. D., R. N. Singh and R. A. Singhal. 1992. Development of Frieswal cattle for higher milk production in India. Proc. $6^{\text {th }}$ AAAP Anim. Sci. Cong. AHAT, Bangkok. 1:161-169.

Nagarcenkar, R. 1983. A model programme for the preservation and genetic improvement of Sahiwal breed in India. Anim. Gen. Resources Info. 1:13-16.

Nay, T. and R. H. Hayman. 1956. Sweat glands in zebu and European cattle. 1. Size of individual glands. Aust. J. Agric. Res. 7:482-494.

Payne, W. J. A. and J. Hodges. 1997. Tropical Cattle-Origins, Breeds and Breeding Policies. Blackwell Science, Oxford (UK).

Raja. 2004. (Ed. B. K. Joshi and A. Singh. 2005) Indigenous Cattle Milch Breeds- Their Potential and Improvement Programmes. VIII National Conference on Anim. Genet. Breed Mathura (UP), India (8-10 March, 2005) pp. 21-28.

Rege, G. E. O., M. A. Lomole and J. W. Wakhungu. 1992. An evaluation of a long term breeding programme in a closed herd in Kenya. I. Effect of non genetic factors on performance and genetic parameter estimates. J. Anim. Breed. Genet. 109 (5):364-373.

Rehman, Z. 2006. Inter-herd performance and genetic evaluation of Sahiwal cattle in Pakistan. Ph.D. Thesis, Univ. Agric. Faisalabad.

Selvi, P. K., J. M. Panandam, K. Yusoff and S. G. Tan. 2004. Molecular characterization of the Mafriwal dairy cattle of Malaysia using microsatellite markers. Asian-Aust. J. Anim. Sci. 17(10):1366-1368.

Singh and Nagarcenkar. 2000. (Ed. B. K. Joshi and A. Singh. 2005). Indigenous Cattle Milch Breeds- Their Potential and Improvement Programmes. VIII National Conference on Anim. Genet. and Breed. Mathura (UP), India (8-10 March, 2005) pp. 21-28.

Singh, S. K. 1992. Factors affecting some milk production efficiency traits in Sahiwal cattle. Indian J. Anim. Sci. 62(4):346-350. 
Singh. 1981. (Ed. B. K. Joshi and A. Singh. 2005) Indigenous Cattle Milch Breeds- Their Potential and Improvement Programmes. VIII National Conference on Anim. Genet. and Breed. Mathura (UP), India (8-10 March, 2005) pp. 21-28.

Syrstad, O. 1990. Mpwapwa cattle: An Indo-Euro-African synthesis. Trop. Anim. Health Prod. 22:17-22.

Talbott, C. W., M. Z. Chauhdry, R. E. McDowell and B. T. McDenial. 1997. Potential to increase milk yield in tropical countries with indigenous dairy cattle. The Sahiwal model. J. Anim. Plant Sci. 7(1-2):1-10.
Visscher, P. M., J. A. Woolliams, D. Smith and J. L. Williams. 2002. Estimation of pedigree errors in the UK dairy population using microsatellite markers and the impact on selection. J. Dairy Sci. 85:2368-2375.

Wellington, K. E. and P. Mahadevan. 1977. Development of Jamaica Hope breed of dairy cattle. FAO Anim. Prod. Health Paper 1:67-72.

Yadav, D. S. and V. K. Dubey. 1979. Development of Karan Swiss. Indian Farm. 28(11):33-35. 